\title{
Analysis of Multiparous Couples' Perceptions of Husbands' Supportiveness for their Wives' Satisfaction during Pregnancy
}

\author{
Kumiko Nakajima, ${ }^{1}$ Sayaka Sawano, ${ }^{2}$ Kyoko Kunikiyo, ${ }^{3}$ \\ Hiroko Arai, ${ }^{2}$ Kaori Tachiki, ${ }^{3}$ Tomoko Fukasawa, ${ }^{3}$ \\ Kikuko Iwanaga $^{3}$ and Yoko Tokiwa ${ }^{3}$
}

\begin{abstract}
This study was conducted to clarify the differences and commonalities in perceptions regarding husbands' supportiveness for their wives' satisfaction during pregnancy between husbands and wives with older children. This report also discusses the effect of nursing care that enhances the supportiveness provided by husbands during their wives' pregnancy. Semi-structured interviews were conducted with two multiparous couples during pregnancy. All interviews were transcribed and a qualitative inductive analysis was performed using Berelson's Content Analysis methods. The following five categories were identified regarding the husbands' supportiveness during their multiparous wives' pregnancy: [Increased consciousness of parenthood toward the unborn baby]; [Empathy regarding wife's physical and mental health arising from the previous pregnancy and childbirth, and addition of a new baby]; [Support with housework to show empathy for the multiparous wife]; [Care of older children to show empathy for the multiparous wife]; [Adjustment of roles in the parenting older children.] From the discussion about the common and different perceptions between multiparous couples, the following suggestion emerges. Nursing care should focus on enhancing the intimacy of a couple, strengthening the family system, increasing consciousness of parenthood toward an unborn baby, and adjusting the role in the parenting of older children. (Kitakanto Med J $2013 ; 63: 51 \sim 59$ )
\end{abstract}

Key words : multiparous couple, wife satisfaction, husband supportiveness, couple perception, marital relationship

\section{Introduction}

In recent years, general supportiveness for pregnant women has decreased in concurrence with the growth of nuclear families and urbanization. Therefore, supportiveness from husbands has become increasingly important. ${ }^{1,2}$ Although it is important for wives to feel satisfied by their husbands' supportiveness during pregnancy, differences exist between husbands and wives regarding the perception of wives' satisfaction with this supportiveness. ${ }^{3}$ Nakajima and Tokiwa $^{4}$ explored perceptions regarding husbands' supportiveness for their wives' satisfaction during pregnancy between husbands and wives, and identified the following three concepts: "intimacy of the couple," "family system," and "consciousness of parenthood."

The research has been conducted regarding the satisfaction of multiparous wives (wives with older children) with their husbands' supportiveness. Some reports suggest that multiparous wives, as compared to primiparous wives, are dissatisfied with their husbands' lack of emotional supportiveness. In particular, dissatisfaction with supportiveness in taking care of the older child can lead to decreased intimacy between the couple. ${ }^{5}$ Moreover, it is a major burden for multiparous pregnant wives to rear older children. One contributing factor to this burden is the lack of

1 School of Nursing, Faculty of Health Science, Gunma Paz College, 1-7-1 Tonya-machi, Takasaki, Gunma 370-0006, Japan

2 Gunma University Hospital, 3-39-15 Showa-machi, Maebashi, Gunma 371-8511, Japan 3 Gunma University Graduate School

of Health Sciences, 3-39-22 Showa-machi, Maebashi, Gunma 371-8514, Japan

Received: December 3, 2012

Address: KUMIKO NAKAJIMA School of Nursing, Faculty of Health Science, Gunma Paz College, 1-7-1 Tonya-machi, Takasaki, Gunma 370-0006, Japan 
cooperation from husbands with regard to child rearing. ${ }^{6}$ These results suggest that multiparous wives expect their husbands to support them emotionally, as well as provide instrumental assistance in rearing older children. Therefore, research suggests that multiparous wives are less satisfied with their husbands' supportiveness than are primiparous wives. ${ }^{1}$ Investigations of satisfaction among couples during pregnancy and after birth have shown that after the birth of the second child, wives tend to feel distant and isolated from their husbands. ${ }^{7}$ At the same time, there is a greater likelihood of decreased satisfaction in the marital relationship. A contributory factor for this decreased satisfaction is the lack of sympathy and supportiveness provided by husbands when responsibilities and burdens related to household chores and child rearing suddenly increase after the birth of a second child. ${ }^{7}$ Multiparous wives might feel that they are receiving insufficient supportiveness from husbands and this can lead to deterioration of the marital relationship during pregnancy, birth, and child rearing. There is a concern that wives' mental health will be negatively affected by declining marital satisfaction. Marital satisfaction and a harmonious relationship between husband and wife during pregnancy are likely to positively affect parent-child relationships. One area in which a harmonious relationship can be beneficial to child rearing is the matched perceptions of husbands and wives' respective roles within the family system. ${ }^{8}$ In other words, it is important that both husbands and wives mutually understand their responsibilities regarding supportiveness and involvement in the marital relationship. Therefore, by forging a relationship in which both wives and husbands understand each other's perceptions regarding husband supportiveness during pregnancy, favorable mental health outcomes can be maintained during the pregnancy.

This study was conducted to clarify the differences and commonalities in perceptions regarding husbands' supportiveness for their wives' satisfaction during pregnancy between husbands and wives with older children. Thus, we investigated how nursing care might contribute toward increase of understanding between couples.

\section{[Operational Definitions of Key Terms]}

Multiparous wife with older children : pregnant wife with at least one older child at home

Wife satisfaction: a feeling of happiness, relief on the part of the wife, or feelings of being supported by her husband

Husband's supportiveness: supportive words, deeds, attitudes, emotions, and intentions on the part of the husband
Couple's perception : perception of the wife towards her husband's supportiveness that the wife feels satisfied ; perception of the husband towards his own level of supportiveness and whether his wife feels satisfied with that supportiveness

\section{Research Methods}

\section{Research subjects}

Two multiparous couples were selected for this study. 26 couples were recruited originally, but 24 couples were excluded because the husbands were unavailable for interviewing due to work obligations or were unable to accompany their wives to a prenatal examination. Informed consents were obtained from the remaining two couples (four people in total) and interviewed them. The inclusion criteria were as follows : no prior history of major abnormalities during past or current pregnancies and no evidence of mental disorder in either partner. The interviews were conducted between July and August 2009.

\section{Methods}

The participating couples were introduced by a midwife who had previously received an explanation of the purpose of this study from us. The midwife consented to cooperate with the study.

Semi-structured interviews were conducted while the couples waited for a prenatal examination. These interviews were recorded and transcribed with the couples' consent. We asked both husbands and wives to talk separately about (1) the situation and scene of husbands' supportiveness for their wives' satisfaction and (2) the husband's supportiveness and the wife's satisfaction (for the husband, we asked about the supportiveness actions he believed his wife perceived as satisfactory). This interview guide was based on Ohinata's study on developmental changes during motherhood, ${ }^{9}$ Nakajima's study on husbands' words, deeds, and attitudes with which their pregnant wives were satisfied, ${ }^{10}$ and research on husbands' supportiveness for their multiparous wives. ${ }^{11,12}$

\section{Ethical considerations}

Participation in the study was voluntary. All couples were provided written and verbal assurance that refusal or exclusion from the study would not affect their medical services or lead to any disadvantages. Consent was obtained after couples had read and understood these terms. This study was conducted with the approval of the Gunma University Graduate School of Medicine Clinical Research Ethical Review Board (approval number 9-14). 


\section{Analytical methods}

Berelson's Content Analysis method ${ }^{13}$ was used for each member of both couples. The interviews were transcribed. A sentence was defined as including a subject and a predicate, narrated by subjects concerning the husband's supportiveness perceived to be satisfactory by the wife. One data unit was defined as a context unit, which was also defined as a recording unit. If plural components of the husband's supportiveness perceived by his wife were found more than once in a single context, each component was separated by category and treated as separate recording units. To analyze partners' perceptions of each other, we compared the recording units of a husband's supportiveness perceived by his wife and a husband's perception of his supportiveness towards his wife. We classified these units into common perceptions by husbands and wives and different perceptions between husbands and wives (wife-only and husband-only perceptions). These recording units were collected, grouped on similarity of content, and codified by abstracting all units. The units were summarized and grouped based on the homogeneity and heterogeneity of their meanings, and then categorized with two steps.

The analysis was conducted under the supervision of a researcher specializing in maternity nursing who is an expert in the qualitative research method. Four researchers who specialize in maternity nursing reproduced the results, and the results were ensured. The rate of concordance was calculated by Scott's equation. Moreover, to increase the precision of categorical classifications, the categorical classification and selection of category names was repeated using the classification results and comments of the four researchers as a reference.

\section{Results}

\section{Subject characteristics}

The subjects were couple A, who were expecting their second child, and couple B, who were expecting their third child. Both wives had a natural pregnancy without complications. Based on the extracted recording units from both couples, we found that the number of prior children did not affect the interview answers that were to be used to examine the couples' perceptions. In addition, both couples' older children were very young. Even if data from both couples were analyzed together, we judged that there was no effect on the wives' or husbands' perceptions. Therefore, we included these two couples in the analysis (Table 1). Interviews were conducted once during the pregnancy in the third trimester for couple A (37 weeks) and in the second trimester for couple B (24 weeks). Each interview lasted an average of 23 minutes (20 to 24 minutes; husbands and wives were interviewed separately).

\section{Husbands' and wives' perceptions regarding wives' satisfaction with husbands' supportiveness}

Eighty-nine recording units were extracted from transcripts of interviews dealing with husbands' and wives' perceptions of wives' satisfaction with husbands' supportiveness. Of those, 28 recording units were common perceptions between the husband and wife, 41were wife-only perceptions, and 20 were husbandonly perceptions. Five categories were common to both husbands and wives (Table 2):

1. [Increased consciousness of parenthood toward the unborn baby]

2. [Empathy regarding the wife's physical and mental health arising from the previous pregnancy and childbirth, and the addition of a new baby]

3. [Support with housework to show empathy for the multiparous wife]

4. [Care of older children to show empathy for the multiparous wife]

5. [Adjustment of roles in parenting older children]

Scott's concordance rate for the category classifications was $83.7 \%$ for perceptions common between husbands and wives, $86.3 \%$ for wife-only perceptions, and $76.3 \%$ for husband-only perceptions, indicating a high degree of reliability.

For each category, we describe subcategories (denoted by 〈angle brackets〉) and recording units

Table 1 Subject's Background

\begin{tabular}{lcc}
\hline & Couple A & Couple B \\
\hline Wife's age & The early 30's & The late 20's \\
Wife's job & House wife & House wife \\
Establishment of the pregnancy & Natural pregnancy & Natural pregnancy \\
Pregnancy progress & Regular progress & Regular progress \\
Husband's age & The late 30's & The late 20's \\
Housband's job & Full-time employment & Full-time employment \\
Older children's age & Frist-born child : 3 years & Frist-born child : 5 years \\
Family structure & Nuclear family & Second-born child : 2 years \\
\hline
\end{tabular}




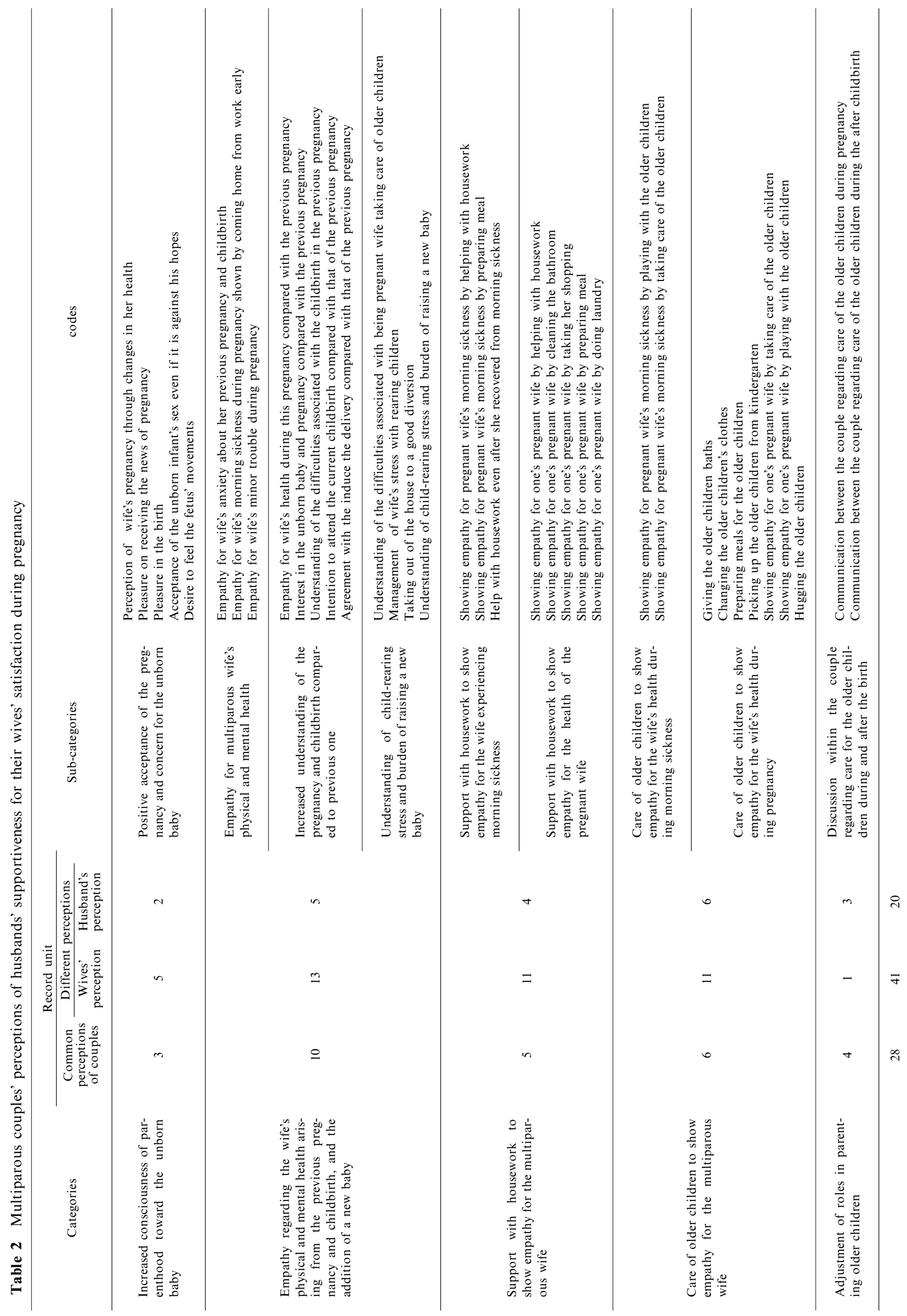


(denoted by $\{$ braces $\}$ ), focusing on the characteristic transcripts of common perceptions and different perceptions between husbands and wives.

1. [Increased consciousness of parenthood toward the unborn baby]

This category included the couple's perceptions toward the husband's supportiveness regarding his positive acceptance of the pregnancy and concern for the unborn baby (Table 2).

$\langle$ Positive acceptance of the pregnancy and concern for the unborn baby consisted of common and different perceptions between the husbands and wives. One common perception was that the wife expressed my husband was happier than I was when I told him about the pregnancy\} and the husband expressed \{I told her, "That's great news" when told of the pregnancy $\}$. Moreover, the wife expressed \{my husband wanted a baby girl, but gradually he warmed up to the idea of a baby boy in my belly\}, whereas the husband expressed \{I told her, "I prefer a baby girl" but in reality, I thought that a baby boy would be acceptable as well $\}$. In one instance of different perception: a husbandonly perception was that he expressed she said, "Touch my belly" so I did because I thought that it satisfied her\}, whereas the wife did not perceive supportiveness from the husband when he was trying to feel the movements of the unborn baby.

2 . Empathy regarding the wife's physical and mental health arising from the previous pregnancy and childbirth, and the addition of a new baby]

This category included the couple's perceptions toward the husband's supportiveness whereby he shows empathy about his pregnant wife's physical and mental health, a greater understanding of the current pregnancy and childbirth than of the previous one, an appreciation of the child-rearing stress brought on by the older children, and an appreciation of the wife's child-rearing burden due to the birth of a new baby (Table 2).

〈Empathy for multiparous wife's physical and mental health $\rangle$ consisted of different perceptions between husbands and wives. The wife expressed a wife-only perception: $\{$ I have a negative image of the previous pregnancy and childbirth, which made me worried about the current pregnancy. When I told him about this, he relieved my anxiety\}, whereas the husband did not perceive that he was being empathic toward the current pregnancy and childbirth. A husband-only perception was that $\{$ I made sure that my wife did not walk too much when we were out because she might feel contractions in her belly\}; whereas the wife did not perceive that the husband was being empathic toward this minor trouble during the pregnancy.
〈Increased understanding of the pregnancy and childbirth compared to the previous one $\rangle$ consisted of common and different perceptions between husbands and wives. An example of a common perception is the wife expressing for the previous childbirth, my husband stopped working and raced to my side during labor, but this time he was suggesting planned childbirth\}, while the husband expressed \{if I am working, I might not be able to go to the hospital right away, so I suggested that planned childbirth might reduce our anxiety\}. An example of a different perception is that the wife expressed that my husband understands the hardships of pregnancy with older children $\}$ and $\{$ my husband understands the hardships of birthing because he was there for our previous childbirth $\}$, whereas the husband did not perceive that he had shown increased understanding of the current pregnancy and childbirth compared to previous times.

〈Understanding of child-rearing stress and burden of raising a new baby consisted of common and different perceptions between husbands and wives. One common perception was that the wife expressed \{being taken out of the house was a good diversion\}, and the husband expressed \{my wife said that being taken out of the house was a good diversion\}. In one instance of different perception, the husband-only perception was that $\{$ I tried to follow up on the older children if they were irritating my wife $\}$, whereas the wife did not perceive supportiveness from the husband regarding his understanding of the stress of child rearing.

3. [Support with housework to show empathy for the multiparous wife]

This category included the couple's perceptions toward the husband's supportiveness by showing empathy for the wife experiencing morning sickness or supportiveness during the pregnancy through housework (Table 2).

〈Support with housework to show empathy for the wife experiencing morning sickness $>$ consisted of perceptions that differed between husbands and wives. The wife-only perception was that $\{$ my husband cooked when I was experiencing morning sickness $\}$, whereas the husband did not perceive that he was being supportive by cooking when she was experiencing morning sickness.

〈Support with housework to show empathy for the health of the pregnant wife $\rangle$ consisted of common and different perceptions between husbands and wives. An example of the common perceptions was the wife expressing \{my husband helped me with shopping because shopping with our older children was difficult $\}$, while the husband expressed $\{$ I tried to go shopping with my wife because the bags can get heavy, and 
it would be harder with our older children $\}$. Another wife-only perception was that it is hard for me to crouch with my belly, so my husband helps with cleaning the bathtub\}, whereas the husband did not perceive that he was showing empathy for his wife by cleaning the bathtub. The husband-only perception was that $\{$ I try to cook whenever I am free, because it looks like my wife is having difficulty\}, whereas the wife did not perceive supportiveness from her husband that was cooking while she was struggling.

4. [Care of older children to show empathy for the multiparous wife]

This category included the couple's perceptions regarding the husband's supportiveness of his wife experiencing morning sickness or supportiveness during pregnancy through caring for the older children (Table 2).

$<$ Care of older children to show empathy for the wife's health during morning sickness $>$ consisted of common and different perceptions between husbands and wives. As an example of common perception, the wife expressed my husband played with the children when I was sick and the husband expressed \{I was able to play with the children when she was sick\}. In one instance of different perception, the wife-only perception was that $\{$ it was very helpful when he looked after the children\}, whereas the husband did not perceive that he was being supportive by taking care of the older children when his wife was experiencing morning sickness.

$<$ Care of older children to show empathy for the wife's health during pregnancy consisted of common and different perceptions between husbands and wives. As an example of common perceptions, the wife expressed $\{$ when my husband is home, he actively bathes the older children $\}$ and the husband expressed \{I take a bath with the older children $\}$. In one instance of different perception, the wife-only perception was that \{my husband helps get the older children changed\}, whereas the husband did not perceive that he helped the older children to get changed. The husband-only perception was that $\{\mathrm{I}$ try to play with the older children because it looks hard for my wife $\}$, whereas the wife did not perceive that her husband was supportive by playing with the older children.

5. [Adjustment of roles in parenting older children]

This category included the couple's perceptions about the husband's supportiveness regarding discussion between the couple about caring for and parenting the older children during and after the birth (Table 2).

〈Discussion within the couple regarding caring for the older children during and after the birth> consisted of common and different perceptions between husbands and wives. As example of the common perceptions is that the wife expressed \{we are in discussion regarding the older children's care $\}$, and the husband expressed \{I think my wife feels stressed about caring for the older children after the new baby is born, so I had a discussion with her\}. In one instance of different perception, a wife-only perception was that we were discussing plans about how to manage with our older children's activities once the new baby is born\}, whereas the husband did not perceive supportiveness while discussing plans for managing older children's activities. A husband-only perception was that we were discussing how to prevent our older children from regressing to a baby state $\}$, whereas the wife did not perceive her husband was being supportive with regard to such a discussion.

\section{Discussion}

\section{Couple's perception of the husband's supportive- ness for his wife's satisfaction}

Five categories were extracted regarding a couple's perceptions of the husband's supportiveness for his wife's satisfaction. The common and different perceptions within the couple are discussed.

1) Common perceptions of the couple regarding husband's supportiveness for his wife's satisfaction [Increased consciousness of parenthood toward the unborn baby]

The wife attempted to share the pleasure of the pregnancy with her husband and her husband's approval of the pregnancy increases her acceptance of the pregnancy. ${ }^{14}$ In the present study, common perceptions between the husband and wife regarding the wife's satisfaction about the husband's positive acceptance of the pregnancy are important for helping the wife accept the pregnancy. Similar results have been reported concerning a couple's first pregnancy. ${ }^{4}$ Moreover, the husbands in the study were able to accept that the unborn baby was not the sex they were hoping for. Such changes in the husband can be understood as signifying an increased awareness of parenthood toward the unborn baby.

[Empathy regarding the wife's physical and mental health arising from the previous pregnancy and childbirth, and the addition of a new baby]

Multiparous wives must physically and mentally prepare for the pregnancy based on experiences from previous pregnancies. ${ }^{15}$ Multiparous wives who had a positive experience with their previous pregnancies are expected to prepare for upcoming pregnancies with positive physical and mental attitudes. However, it is essential that for those women with unsatisfactory prior pregnancies, couples communicate so that husbands understand the hardships of pregnancy and can accommodate the wishes of their wives during birth. 
The mental benefits promoted by couple's cooperative actions during the pregnancy are an important factor for maintaining the marital relationship ; furthermore, these benefits can lead to increased intimacy. ${ }^{16}$ Therefore, a couple's intimacy develops as spouses work together to ensure a satisfactory pregnancy and childbirth.

[Support with housework to show empathy for the multiparous wife]

Husbands' empathetic supportiveness through help with housework not only works directly to release wives from the stress of housework but also lightens the spirits of pregnant wives due to husbands' thoughtfulness. ${ }^{14}$ The multiparous wives in this study were likely to experience physical and mental burdens because of the pressures of housework and care of older children. Husbands' help with household chores can be thought of as a supportive response to their wives' complaints about their physical burdens. Within the married life theory of Scanzoni and Scanzoni, ${ }^{16}$ stability of the family system is an essential factor for maintaining a healthy marital relationship. The authors also stress that sharing housework duties between the husband and wife is important for maintaining the family system. The common perception within couples regarding wives' satisfaction of husbands' supportiveness through housework generates the feeling of mutual support.

[Care of older children to show empathy for the multiparous wife]

Multiparous wives expect their husbands to help raising older children due to the physical burden of the pregnancy and the physical/mental burdens of caring for older children. ${ }^{5}$ The multiparous wives in this study expected their husbands' direct supportiveness through caring for the older child during times of morning sickness. These results showed a match between the expectations of multiparous wives and their husbands' supportiveness. Husbands helping with the rearing of older children enable their wives to feel supportiveness, lead to a stable family system and improve mental health.

[Adjustment of roles in parenting older children]

Multiparous couples must make adjustments to their relationships in preparation for the necessary care and rearing of the newborn baby as well as the older children during the pregnancy. ${ }^{17}$ The couples in this study discussed the raising of the older children after the birth of the newborn baby. Common perceptions of wives' satisfaction toward adjustments to parental duties during pregnancies are important for restructuring family relationships to include the older children, as well as the newborn baby.

2 ) Different perceptions of couples regarding hus- bands' supportiveness for their multiparous wives' satisfaction

[Increased consciousness of parenthood toward the unborn baby]

In terms of multiparous wives' awareness of parenthood, mothers loosen their bonds with the older children to care for the newborn baby, and they feel confusion and powerlessness for taking care of the older children. ${ }^{17}$ Because multiparous couples already have awareness of parenthood toward their older children, this awareness may hinder their awareness about the unborn baby during pregnancy. Different perceptions within the couple are a husbands' supportiveness, such as an action of feeling the movements of the fetus. The different perception can hinder the development of parenthood toward the unborn baby. Therefore, the relationship of understanding each other within a multiparous couple is important for the development of parenthood toward unborn baby.

[Empathy regarding the wife's physical and mental health arising from the previous pregnancy and childbirth, and the addition of a new baby]

The multiparous husbands considered that their wives were satisfied because their husbands' actions addressed minor trouble related to the current pregnancy. However, the multiparous wives did not express this perception. These points suggest a difference in awareness between wives and husbands, a result that was previously reported in a study of primiparous couples. ${ }^{4}$ Similar to primiparous wives, multiparous wives hope that their husbands empathize when they are anxious about the pregnancy or birth or when they are experiencing morning sickness. In such situations, husbands' supportiveness is more likely to be perceived as satisfactory. However, husbands' supportiveness that does not match their wives' feelings, even if the actions/words were meant to be considerate, might not be as beneficial.

[Support with housework to show empathy for the multiparous wife]

Research investigating the influence of husbands' supportiveness for their wives' mental states shows that multiparous wives expect and seek mental support from their husbands. ${ }^{5}$ The present study shows similar results to the previous research. Wives feel satisfaction because their husbands show a greater understanding for the pregnancy and childbirth as compared to the previous pregnancy and childbirth. A couple's intimacy is signified by communication between the couples. Intimacy, at its core, is the reaffirmation of each other's presence through words and deeds. ${ }^{18}$ For this reason, it is important that wives expression of appreciation toward their husbands' supportive actions 
promotes the empathy within couples.

[Care of older children to show empathy for the multiparous wife]

Okayama and Takahashi ${ }^{15}$ report that the relationship with husbands is an important factor in the experience of anxiety among multiparous wives during the first trimester. Wives are susceptible to hardships caused by morning sickness during the first trimester, which can lead to a negative psychological state. Furthermore, wives must also ensure that the older child is cared for and that the housework is done, which puts additional physical and mental burdens on wives; this necessitates husbands' supportiveness. The present study shows that physical and mental burdens are reduced through husbands' supportiveness. The wives are satisfied with their husbands' thoughtfulness. As a result, when wives show appreciation toward their husbands for supportive actions, such as helping with housework or caring for older children in case of morning sickness, couples can take joint ownership of their feelings and increase husbands' supportiveness and perceive satisfaction among wives.

[Adjustment of roles in parenting older children]

Regarding child rearing roles, there is a trend for the interests of husbands to turn toward playing with the children rather than cope with the basic needs of the children. ${ }^{19}$ In the present study, wives perceived their husbands' actions of feeding and changing the clothes of their older children (traditionally viewed as part of wives' roles) as motivated by their empathy towards the wives' health. In contrast, husbands viewed their role as playing with their children and their wives were satisfied because the husbands were fulfilling that role. Consequently, it is important that both partners in a multiparous couple understand that the husband's cooperation with his wife in parenting the older children forms the basis for the restructuring of their family system.

\section{Nursing care that increases husbands' supportive- ness for the satisfaction of their multiparous wives}

Among multiparous couples, on the basis of the experience of the previous pregnancy and delivery, nurses are expected to cooperate with couples in order to ensure the well-being of this pregnancy and delivery. Therefore, it will be important for nursing care to encourage improved intimacy within the couple so that a favorable communication system allows for the exchange of husbands' thoughtfulness and wives' appreciation.

Moreover, nursing care to promote a stable family system through understanding each other's role with regard to housework and child rearing duties for older children, while being mindful of multiparous wives' health, is also important. Partial shouldering of housework and child-rearing duties on the part of the husband is a basis for a stable family system and contributes to reducing physical/mental burdens on multiparous wives.

For multiparous couples, the awareness regarding parenting of their older children may adversely affect their attitude toward the unborn baby during pregnancy. Therefore, nursing care should encourage the development of a shared perception of parenthood regarding the unborn baby between parents as well as promote acceptance of the pregnancy and other such positive attitudes in the parents. Moreover, couples should constantly communicate regarding childrearing matters during the pregnancy. This study also recommends that support be provided for couples to reconstruct family relations, including the older children and the newborn baby. Nursing care to facilitate the readjustment of parental roles for older children is important.

\section{Conclusion}

This study clarified the common and different perceptions held by multiparous couples regarding husbands' supportiveness for their wives' satisfaction. Five categories were extracted regarding husbands' supportiveness: (1) increased consciousness of parenthood towards the unborn baby; (2) empathy regarding the wives' physical and mental health arising from the previous pregnancy and childbirth, and the addition of a new baby; (3) support with housework to show empathy for the multiparous wife; (4) care of older children to show empathy for the multiparous wife; and (5) adjustment of roles in parenting older children. Intimacy within the couple and the family system, realization of parenthood toward an unborn baby, and adjustment of roles in the parenting of older children are important for nursing care that enhances multiparous wives' satisfaction toward their husbands' supportiveness.

This study analyzed linguistic descriptors of interviews conducted on multiparous couples ${ }^{13}$ and defined the multiparous couples' perceptions based on an analysis of these descriptors. Accordingly, some perceptions may not have been recorded, even though the couples were actually aware of certain perceptions. As a result, future interventional studies of nursing care for enhancing multiparous wives' satisfaction toward their husbands' supportiveness should keep in mind the limitations of our research methods. Although the research subject is only two couples, some conclusions were derived for husbands' and wives' perceptions regarding multiparous wives' satis- 
faction with their husbands' supportiveness.

\section{Acknowledgements}

We would like to thank the couples who cooperated with us for this study.

\section{References}

1. Iwata G, Watanabe A, Yanagihara $\mathrm{M}$, et al. Ninpu no stress niyoru kibun no henka to social support no kanren. Journal of Comprehensive Nursing Res 2000 ; 3(1) : 21-27 (in Japanese).

2. Ohinata M. Atarashii kazoku no tanjyo to souzou. Annual Report on Family Psychology. 9. Tokyo: Kanekoshobo, 1991 ; 25-38 (in Japanese).

3. Teraguchi J, Kawahara M, Kadota K, et al. Ninshinchu no tuma to otto no ninshiki no sai -otto no tuma heno kitaido to sono manzokudo nituite- . Maternal Health 1997 ; 38(2) : 159-166 (in Japanese).

4. Nakajima K, Tokiwa Y. Analysis of couples' awareness about husbands' support for their wives' satisfaction during the early phase of pregnancy. Japan Acad Midwifery 2011 ; 25(1) : 45-56 (Abstract in English).

5. Wakita M, Kojima $Y$, Irisawa $M$. Ninshin/shussan ga hahaoya no shinri ni oyobosu eikyou -otto karano support ni chumokushite-. Maternal Health 2003 ; 44(2) : 244-249 (in Japanese).

6. Kojima Y, Irisawa M, Wakita M. Dainishi ninshinkikanchu niokeru hahaoya-daiisshi kankei. Maternal Health 2003 ; 44(2) : 289-299 (in Japanese).

7. Horiguchi M. Marital relationship in the transition to parenthood: A comparison of marital satisfaction between expectant couples and parental couples. J Soc Sci Family Stud 2000; 7 : 81-95 (in Japanese).

8. Takahashi M, Akiyama T. Ningen kankei no shinri to rinshou. Kyoto : Kitaohjishobo, 1995 ; 42-67(in Japanese).

9. Ohinata M. Bosei no kenkyu. Tokyo: Kawashima- shoten, 1988; 71-105 (in Japanese)

10. Nakajima K. Husbands' act and attitude satisfactory to pregnant women -characteristics of each pregnant period-. J Japan Soc Maternal Nurs 2006; 6(1) : 15-21 (Abstract in English).

11. Hinokuma F, Fujiwara C, Ishii K. A study on parental development -Focusing on fathers sharing housework and taking care of 18-month old children-. J Japan Acad Midwifery 1999; 12(2) : 56-63 (Abstract in English).

12. Tachibana C, Nakamura E, Nakajima Y, et al. Behavioral characteristics of husbands in child rearing and housework and relationships with attachment to their children and satisfaction of husband and wife's relationships : compared with their wives. Maternal Health 2008; 49(1): 65-73 (Abstract in English).

13. Berelson B. Content Analysis. Translated by Michio Inaba. Tokyo: Misuzushobo (in Japanese).

14. Shindo $\mathrm{S}$, Wada $\mathrm{S}$. Bosei no shinrishakaitekisokumen to kango care. Tokyo: Igakushoin, 1990 ; 2-57(in Japanese)

15. Okayama $\mathrm{H}$, Takahashi $\mathrm{M}$. Research on anxiety in primiparous and multiparous wives - influence of psychological and social aspects during the first, second and third trimesters. J Soc Nurs Health Care 2005 ; 7(1) : 18-25 (in Japanese)

16. Scanzoni LD, Scanzoni JH. Men, Women, and Change, A Sociology of Marriage and Family. New York: McGraw Hill, 1988 ; 239-418.

17. Rubin R. Theory of Maternal Identity - Maternal Identity and the Maternal Experience. Translated by Sachie Shindo and Keiko Goto. Tokyo: Igakushoin, 1997; 45-82 (in Japanese)

18. Hirayama J. Theory and Practice of Clinical Supports for Parenting. Journal of Japan Society of Family Psychology. Tokyo: Kanekoshobo, 2002; 63-76 (in Japanese).

19. Harmon Hanson SM, Boyd ST. Family Health Care Nursing - Theory, Practice and Research. Translated by Murata K, Arakawa Y, Tsuda N (supervisor). Tokyo: Igakushoin, 2001 ; 118-138 (in Japanese). 